\title{
"Nosotros: el público ilustrado". Para una breve genealogía de los modos contemporáneos de crítica
}

\author{
Pablo Martín Méndez ${ }^{1}$ \\ pablomartinmendez@hotmail.com
}

\section{Resumen}

Entre los años 1978 y 1979, en un breve pasaje de sus trabajos e investigaciones, Michel Foucault advierte el pronto advenimiento de un "nuevo orden interior". Se trata de un pasaje fugaz, que hasta ahora no ha sido explorado en todos sus alcances. Este artículo retoma los interrogantes allí abiertos, poniendo especial atención en el surgimiento histórico del "publico" como sujeto crítico. De alguna manera, es el público y sus modalidades de subjetivación lo que el nuevo orden interior pone en juego. ¿Cómo se constituye hoy en día el público?, ¿cuáles son sus relaciones y tensiones con el poder? Foucault esboza algunas respuestas en el curso Naissance de la Biopolitique, sobre todo en las clases que abordan las condiciones de emergencia del "neoliberalismo". Más que una simple ideología económica, habría que concebir al neoliberalismo como una forma de diferenciación ante el poder, un posible modo de constituirse como público crítico. La pregunta por el nuevo orden interior debe considerar este último punto, advirtiendo, tal y como Foucault habría advertido en su momento, que nuestras actuales críticas contra el Estado tienen en gran parte una oscura procedencia neoliberal.

Palabras clave: racionalidad de gobierno - crítica moderna - liberalismo neoliberalismo - fobia al Estado

\section{Abstract}

Between the years 1978 and 1979, in a passage of his works and research, Michel Foucault warns the advent of a "new inner order". It is a fleeting passage, which until now has not been explored in all its scope. This article takes up the questions opened by Foucault, paying special at-

1 Doctor en Filosofía por la Universidad Nacional de Lanús. Licenciado y Profesor en Ciencia Política por la Universidad de Buenos Aires. Becario Postdoctoral CONICET (2017-2019). Profesor adjunto en la Maestría en Metodología de la Investigación Científica, profesor titular de Fundamentos de Ciencia Política de la Licenciatura en Ciencia Política y Gobierno, y en el área "Ética" de la Universidad Nacional de Lanús. 
tention to the historical emergence of the "public" as a critical subject. In some way, it is the public and its modes of subjectivation which the new order brings into play. How is the public configured today? What are their relationships and tensions with power? Foucault outlines some answers in the course Naissance de la Biopolitique, especially in classes where he analyzes the conditions of emergency "neoliberalism". More than a simple economic ideology, neoliberalism should be conceived as a form of differentiation vis-à-vis power, a possible way of establishing itself as a critical public. The question of the new internal order must consider this last point, warning, as Foucault would have warned in his moment, that our current criticisms of the state have in some points a dark neoliberal legacy.

Key words: governmental rationality - modern criticism - liberalismneoliberalism - State phobia

\section{Introducción}

¿Qué somos hoy?, ¿cómo pensar el presente en el cual vivimos y desde el cual hablamos?, ¿de qué manera ser otros? He aquí algunas de las preguntas que Michel Foucault planteaba poco antes de su muerte; para nosotros, los que hablamos actualmente con Foucault y a partir de Foucault, son también un modo específico de continuar haciendo filosofía, de llevar al pensamiento hasta sus propios límites.

Existen diferentes formas de contestar aquellas preguntas, todas lícitas y sin duda necesarias. Así por ejemplo, bien podríamos reconstruir y profundizar las investigaciones foucaultianas sobre las tecnologías políticas de normalización, prestando especial atención a lo que el texto La voluntad de saber dio en llamar "biopolítica". Esto resultaría importante para comprender el modo en que el poder nos ha constituido como sujetos; de hecho, sería una de las tantas vías que nos conduciría de lleno hasta la problematización del presente. Otra vía a seguir, también importante e imprescindible en nuestros días, consistiría en ampliar las investigaciones de Foucault sobre las prácticas de sí greco-romanas, particularmente aquellas que se explayan en los textos El uso de los placeres y La inquietud de sí. No se trataría de hacer una simple descripción histórica, sino más bien, y como ya advirtiera Foucault, de problematizarnos a nosotros mismos; más concretamente, se trataría de analizar las prácticas mediante las cuales hemos llegado a constituirnos como sujetos de nuestra propia conducta moral. Hay sin embargo un camino adicional, y es el que nosotros querríamos proponer a lo largo de este escrito.

Luego de abordar la biopolítica, y un poco antes de internarse definitivamente en el estudio de las prácticas de sí greco-romanas, Foucault se preguntará por las especificidades y las diferencias constitutivas de nuestro actual "orden interior". Nos referimos a la conferencia titulada como "Nuevo orden interior y control social" (1991 [1978]), pero además a la segunda parte del curso Nacimiento de la biopolitica (2008a [1979]). De alguna manera, allí Foucault entrevé la alteración de la actual dimensión pública; precisamente aquella donde Kant encontraba la posibilidad de ilustrarse a sí mismo, usando la propia razón sin relación de obediencia o de autoridad. Pues bien, el camino que proponemos ahora consiste en reto- 
Pablo Martín Méndez / "Nosotros: el público ilustrado”. Para una [...] /69 mar las interrogaciones de Foucault sobre el actual orden interior, preguntándonos concretamente cómo, a través de qué prácticas y relaciones, se constituye hoy en día el "público".

\section{Dentro y fuera del liberalismo}

Conviene hacer una aclaración de entrada: el público del que aquí hablamos, y del que también parecería hablar Foucault en diferentes ocasiones, puede pensarse de varias maneras menos como un grupo de individuos expectantes, a la espera de ser conducidos y hasta manipulados por alguien, sin ninguna iniciativa y capacidad de reacción. El público no es, o acaso no ha sido siempre, un mero objeto de estudio y de análisis; de hecho, tampoco alcanza con ver allí la superficie de innumerables sondeos estadísticos. Hay que pensar la cuestión desde otra perspectiva: más que un objeto aislable y perfectamente manejable, el público se define siempre en relación. Diríase que el público está relacionado con tres cuestiones complementarias: en primer lugar, con una coyuntura histórica bien precisa: la Europa de fines del siglo XVIII, signada por una ola de revoluciones políticas, económicas y culturales de diferente alcance; en segundo lugar, con el modo en que, durante ese mismo período histórico, el poder no sólo es ejercido, sino además cuestionado e incluso resistido; y finalmente, con la emergencia de lo que ha dado en llamarse la "crítica moderna". Genealogía, poder y crítica: si realmente el público nos indica algo acerca de nosotros mismos, lo hace siempre en relación a todo esto.

Cuando Foucault habla sobre el público se sitúa en un contexto histórico concreto, un campo de emergencia que, por muchas razones, resulta de enorme importancia para entender nuestro presente. Estamos refiriéndonos a las últimas décadas del siglo XVIII. ¿Qué sucedía en aquél momento? Desde fines del siglo XVIII, y hasta bien entrado el siglo XX, va desarrollándose y cobrando cada vez más fuerza una "racionalidad" específica de gobierno. Se trata de un entramado de procedimientos, análisis y cálculos políticos; es toda una manera de percibir y de resolver problemas conforme a ciertos fines de gobierno. El objeto de intervención principal de esa racionalidad emergente estaría en la población, su forma de saber en la economía política, mientras que sus instrumentos técnicos más fundamentales serían los dispositivos de seguridad. Sin duda alguna, resuenan aquí muchas de las cuestiones por las cuales Foucault se ha interesado en otros momentos: como las tecnologías biopolíticas y disciplinarias, también el biopoder, e igualmente, o quizá ya en el límite, la red de dispositivos inmanentes a las sociedades de normalización.

Ahora bien, los cursos Seguridad, territorio y población y Nacimiento de la biopolítica dejan entrever una cuestión adicional, y es que todo ese entramado de tecnologías, cálculos y saberes está atravesado por el "liberalismo" como racionalidad gubernamental específica. Precisamente allí, más que en ningún otro lugar, debe situarse al público:

La palabra no es nueva, aunque sí su uso. El público, noción capital del siglo XVIII, es la población considerada desde el punto de vista de sus opiniones, sus maneras de hacer, sus comportamientos, sus hábitos, sus temores, sus prejuicios, sus exigencias: el conjunto susceptible de sufrir la influencia de la educación, las campañas, las convicciones. (Foucault, 2006, p. 102) 
El público aparece en el extremo de la población misma; de alguna manera, es la población considerada desde un punto de vista a-orgánico, no necesariamente biológico. Al menos así lo daría a entender Foucault: "De la especie al público tenemos todo un campo de nuevas realidades" (Foucault, 2006, p. 102).

Maurizio Lazzarato, un filósofo italiano que intenta profundizar las problemáticas abiertas por Foucault, parecería ir todavía más lejos:

El "público" no es un hecho social estático reducible a un organismo, sino una variación, una tendencia, un devenir. [...] La multiplicidad, en el público, tiende a volverse simultáneamente molecular e inmediatamente colectiva y a asumir la forma del flujo, de la variación, de la velocidad [...]. El público, en efecto, es un acontecimiento. (Lazzarato, 2006, p. 74)

Nosotros diríamos también que el público se ubica en el límite de las tecnologías liberales de gobierno; es el acontecimiento que las disciplinas y la biopolítica nunca logran encauzar y ni regular del todo. Ciertamente, el público no cabe en los reducidos espacios de la disciplina, aunque tampoco se lo puede situar sin más en los espacios abiertos de la biopolítica; no puede gobernarse de igual manera en que se gobierna a los organismos individuales, ni regularse como se regulan habitualmente las poblaciones. Para la racionalidad liberal de gobierno, hay aquí todo un desafío, un acontecimiento, y en última instancia un límite.

¿Por qué decimos que el público está en el límite del liberalismo? Volvamos brevemente al siglo XVIII; o en otros términos, a aquello que dio en llamarse l'âge des Lumières [la época de las Luces]. Foucault ha sostenido que esa época estuvo marcada por una profunda obsesión, prácticamente un miedo:

Un miedo obsesivo recorre el siglo XVIII: el espacio oscuro, la pantalla de oscuridad que impide la visibilidad de las casas, las gentes, las verdades. Disolver los fragmentos de noche que se oponen a la luz, hacer que no existan más espacios oscuros en la sociedad, demoler esas cámaras negras en las que se fomenta la arbitrariedad política, los caprichos del monarca, las supersticiones religiosas, los complots de los tiranos y los frailes, las ilusiones de ignorancia, las epidemias. (Foucault, 1980, p. 16)

La racionalidad liberal tiene un problema de fondo, que consiste en disolver cualquier punto donde se acumulen la superstición y la ignorancia, cualquier estrato demasiado oscuro que sirva de apoyo para la arbitrariedad y el despotismo. ${ }^{2}$ A la ignorancia y la superstición se les debe anteponer entonces una mayor "libertad"; más específicamente, hay que contrarrestarlas dejando que las ideas y las creencias circulen libremente, sin formar estratificaciones o complots potencialmente peligrosos.

2 Vale recordar aquí las palabras de Mercier de la Rivière, un fisiócrata francés del siglo XVIII: "El despotismo arbitrario, producción propia de la ignorancia, es una fuerza física que se sirve de su superioridad para oprimir. Esta fuerza no existe por sí misma, ni en un solo individuo, sino que es el resultado de una asociación; y esta asociación se forma precisamente de un concurso de pretensiones y de intereses arbitrarios unidos a éste efecto (de la Rivière, 1823, p. 314). 
Pablo Martín Méndez / "Nosotros: el público ilustrado". Para una [...] /71

Los gobiernos liberales sólo funcionan bien cuando existen y quedan aseguradas una serie de libertades concretas, incluyendo no únicamente la libertad de mercado o de circulación de bienes, sino a la larga la libertad de ideas:

[...] libertad de mercado, libertad del vendedor y el comprador, libre ejercicio del derecho de propiedad, libertad de discusión, eventualmente libertad de expresión. [...] la nueva razón gubernamental tiene necesidad de libertad. [...] Está obligado a producirla y está obligado a organizarla. (Foucault, 2008a, p. 84)

Si la gubernamentalidad liberal produce libertad, es porque encuentra en ella un contra-efecto para las supersticiones y las arbitrariedades políticas que de allí se siguen. Hecho curioso, y quizá más importante de lo que perecería a primera vista -sobre todo cuando se trata de pensar los alcances y las limitaciones de una determinada práctica de gobierno-. Según Foucault, desde cierto momento histórico los "dispositivos liberógenos", los saberes y las tecnologías productoras de libertad, redundaron en efectos opuestos a los que se esperaban. Así sucedió con la libertad de producción y de comercio, que desde finales del siglo XIX, y tal como pudo percibirse aquí y allá, reportaron un enorme peligro para la libertad económica y política de los trabajadores industriales; pero así también con las libertades de trabajo, cuyos mecanismos de protección fueron a su vez percibidos como una amenaza para la libertad de producción y de comercio. No otra es la encrucijada del liberalismo, donde los dispositivos de producción y promoción de las libertades ponen en peligro a las libertades mismas: "Ése es el equívoco de todos los dispositivos [...] 'liberógenos', todos esos dispositivos destinados a producir liberad y que, llegado el caso, corren el riesgo de producir exactamente lo contrario". (Foucault, 2008a, p. 91)

De más está decir que el público emerge en relación con los dispositivos liberógenos, especialmente con aquellos destinados a garantizar la libertad política y la libertad de expresión. Bajo el objetivo de contrarrestar los focos de arbitrariedad, o por necesidad de disolver los puntos de ignorancia y de superstición, el gobierno estimula la mayor circulación posible de ideas y creencias; en simples palabras, permite que poco a poco vaya conformándose un nuevo espacio público. Ahora bien, tal vez no sea demasiado aventurado sostener, como nosotros sostendremos en adelante, que la libre circulación de ideas y creencias tuvo un efecto sumamente inesperado. Lo que en principio debía servir al sostenimiento de los gobiernos liberales, se vuelve eventualmente en su contra. Y es que, en el límite, el público no sólo critica los focos de arbitrariedad, sino además las incongruencias y los peligros provocados por la propia racionalidad liberal de gobierno. De hecho, muchos descubrirán que los gobiernos liberales bien pueden conducir hacia la arbitrariedad y el exceso mismo de poder.

\section{Diferenciarse del poder}

A fines del siglo XVIII, en aquel interesante artículo titulado Was ist Aufklärung? [¿Qué es la Ilustración], Kant solicitaba a los príncipes dejar al público en libertad de ilustrarse a si mismo; esto es, usando la propia razón sin relación de obediencia o de autoridad: "resulta posible que el público se ilustre a sí mismo, algo que es casi inevitable 


\section{2/ Perspectivas Metodológicas /19/Vol. II /Año 2017}

si se le deja en libertad" (Kant, 2005, p. 22). Cabe remarcar aquí un par de cuestiones complementarias: la primera está explicitada por Kant, mientras que la otra aparece de una manera más implícita.

Tal y como se desprende del texto Was ist Aufklärung?, existen dos usos posibles de la razón, a saber: el "uso público" y el "uso privado". Así pues, el uso público nos constituye como sujetos universales; o en los términos de Kant, como "doctos" capaces de atener nuestro propio juicio a la razón total de la humanidad: "Entiendo por uso público de la razón el que alguien hace de ella en cuanto docto (Gelehrter) frente al gran público del mundo de los lectores" (Kant, 2005, p. 23). El uso privado de la razón se ubicará en un terreno distinto: no es el que hacemos como miembros del público, en cuanto doctos que hablan ante la razón total de la humanidad, sino más bien como miembros pasivos del Estado. Por un lado el uso público de la razón, y por el otro el uso privado; aquí la crítica y allá la obediencia. No es que ambos usos sean contradictorios o excluyentes; en todo caso, funcionan en dimensiones distintas: justamente en la dimensión pública y la dimensión privada, o también en el espacio de la crítica y en el de la obediencia.

La segunda cuestión aparece en forma más implícita, y es en realidad Foucault quien después se encargará de remarcarla. Ocurre que el uso público de la razón implica o supone en el límite todo un trabajo de sí sobre sí mismo: "Los hombres salen gradualmente del estado de rusticidad por su propio trabajo, siempre que no se los intente mantener, adrede y de modo artificial, en esa condición" (Kant, 2005, p. 27). Para salir de la rusticidad o la pasividad en la cual nos encontramos inmersos, para abandonar lo que Kant llamará igualmente como "minoría de edad", hace falta un trabajo de sí sobre sí. Se trata de asumir otra "actitud", otro modo de relación consigo mismo y con los demás. Foucault hablará sobre la voluntad de no ser gobernado de determinada manera, o también del intento de "diferenciarse" ante los poderes existentes: "una cierta voluntad decisoria de no ser gobernado, una voluntad decisoria como actitud a la vez individual y colectiva de salir, como decía Kant, de la minaría de edad. Cuestión de actitud" (Foucault, 1995, p. 17). La especificidad de la crítica moderna reside justamente allí: en el cambio de actitud alrededor del gobierno. Ser moderno equivale a asumir una actitud crítica, mientras que actuar críticamente resulta propio de todo aquel que ya no quiere ser gobernado de esta manera, bajo estos fines y por medio de estas técnicas: "no de esa forma, no para eso, no por ellos" (Foucault, 1995, p. 7). La actitud moderna estará presente tanto en Kant como en el Aufklärung; así también, marcará el horizonte de emergencia del público.

El público emerge de un juego de diferenciaciones con el poder; más aún, es todo un espacio de crítica contra las extralimitaciones y los abusos de las autoridades instituidas. Foucault señalará que las diferentes maneras de usar la razón, donde se obedece al poder en cuanto ciudadano y se lo critica en cuanto docto, abren una nueva labor para la actividad filosófica:

[...] desde Kant el papel de la filosofía ha sido el de impedir que la razón sobrepase los límites de lo que está dado en la experiencia; pero desde esta época -con el desarrollo de los Estados modernos y la organización política de la sociedad- el papel de la filosofía también ha sido el de vigilar los abusos del poder de la racionalidad política. (Foucault, 2008b, p. 96). 
Pablo Martín Méndez / "Nosotros: el público ilustrado". Para una [...] /73

La crítica moderna ya no consiste únicamente en marcar los límites legítimos del conocimiento, aquellos a partir de los cuales la razón se torna heterónoma o queda a merced de una autoridad externa; además de eso, o junto con eso, aparece poco a poco la cuestión del poder. En otras palabras, y aquí habría que inscribir toda una rama del pensamiento moderno, se plantea la sospecha o la interrogación sobre las relaciones entre la razón y el poder, el uso de la razón y los efectos de poder que ésta conlleva. Durante la primera mitad del siglo XX, varios serán los participen de semejante sospecha; no sólo Max Weber y después la Escuela de Frankfurt, sino igualmente una parte nada menor del público alemán de izquierda:

[...] esta sospecha de que hay algo en la racionalización y quizá incluso en la razón misma que es responsable del exceso de poder, pues bien, esta sospecha se ha desarrollado especialmente en Alemania y, digamos, para ser aún más breves, que se ha desarrollado en lo que podríamos llamar una izquierda alemana. (Foucault, 1995, p. 10)

Muchas cosas han trascurrido desde entonces; varios acontecimientos de los cuales también Foucault fue testigo.

¿Cómo se ejerce hoy la crítica?, ¿de qué manera nos diferenciamos ante el poder y sus excesos? En el curso Nacimiento de la biopolítica, Foucault otorga algunos indicios sobre el caso; de hecho, sostiene que la crítica moderna ha devenido en toda una sospecha antiestatal, una intensa y diseminada fobia al Estado:

[...] lo que se pone en cuestión en la actualidad, y a partir de horizontes extremadamente numerosos, es casi siempre el Estado; el Estado y su crecimiento indefinido, el Estado y su omnipresencia, el Estado y su desarrollo burocrático, el Estado con los gérmenes de fascismo que conlleva, el Estado y su violencia intrínseca debajo del paternalismo providencia. (Foucault, 2008a, p. 218)

Aquí se habla de intervenciones autoritarias, allí de fascismo e incluso de totalitarismo, en última instancia: la mayor parte del público supondría hoy que el Estado, ya sea por derecha o por izquierda, ya por defecto o por omisión, se encuentra siempre presto a degenerar en lo peor.

Sin importar cuál sea su orientación económico-política, el Estado irá indefectiblemente para peor. Tan es así que nuestros actuales modos de crítica terminarían percibiéndolo como una gran sombra vertida sobre la sociedad civil; o, en términos de Foucault, como un "fantasma paranoico y devorador": "en nombre del dinamismo del Estado, siempre se puede encontrar un parentesco o un peligro, algo así como el gran fantasma del Estado paranoico y devorador. En este sentido, poco importa en definitiva qué influjo se tiene sobre lo real o qué perfil de actualidad presente éste" (Foucault, 2008a, p. 220). De un lado estaríamos nosotros, el público capaz de constituirse y de actualizarse a sí mismo mediante la crítica, y del otro el Estado, que por defecto intrínseco resulta demasiado inactual o poco adaptado a estos tiempos. Ahora bien, mientras más inactual es el Estado, mientras más dificultad encuentra para adaptarse a las exigencias de nuestro presente, más omnipresente 


\section{4/ Perspectivas Metodológicas /19/Vol. II /Año 2017}

y avasallante se torna. De manera tal que el problema no residiría en la simple avidez de poder, sino en algo peor: en la completa ineptitud de las estructuras estatales.

\section{La oscura procedencia}

Ya en la década de 1970, Foucault advertía que ese modo de crítica -el cual es también, cabe recordarlo siempre, un modo de relación consigo mismo y de diferenciación ante el poder- estaba difundido en casi todas partes, tanto como para obturar cualquier otro tipo de análisis y de problematización sobre la actualidad: "Basta con encontrar, a través de la sospecha y (...) de la denuncia, algo parecido al perfil fantasmático del Estado para que ya no sea necesario analizar la actualidad" (Foucault, 2008a, 220-221). De ahí lo que nosotros entendemos como una de las apuestas más importantes de Foucault. Para pensar el presente a fondo y hasta las últimas consecuencias, tenemos que preguntar de dónde nos llega la crítica antiestatal: "la crítica por el dinamismo del Estado (...) no busca saber de dónde viene esa especie de sospecha antiestatal, esa fobia al Estado que circula hoy en tantas formas diversas de nuestro pensamiento" (Foucault, 2008a, p. 221). Apuesta importante aunque inclusa; en realidad, sólo la segunda parte del curso Nacimiento de la Biopolitica se dedicará a brindarle cierta atención. El resto nos corresponderá a nosotros, los que hablamos hoy desde Foucault y también más allá de Foucault.

Preguntemos entonces de dónde procede -o mejor aún: a través de qué acontecimientos nos viene- la sospecha antiestatal. La respuesta de Foucault dirigirá nuestra mirada hacia un lugar y un momento histórico concreto: la Alemania de las décadas de 1930 y 1940. Fue en ese momento cuando un grupo de doctos quiso diferenciarse ante los poderes existentes; fue especialmente allí, más que en ningún otro lugar, donde se percibió al Estado como una entidad polimorfa, omnipresente y avasallante. El hecho fundamental, y quizá impensado para los actuales modos de crítica, consiste en que aquellos doctos solían definirse a sí mismos con una divisa o un distintivo; esto es, el "neoliberalismo":

[...] en la escuela neoliberal alemana hallamos el análisis de los parentescos necesarios entre las diferentes formas estatales y la idea de que el Estado tiene una dinámica propia por la que jamás puede detenerse en su ampliación y en su cobertura de la totalidad de la sociedad civil. (Foucault, 2008b, p. 221).

Así como hemos intentado pensar al público desde una perspectiva diferente, así también deberíamos proceder con el neoliberalismo. En efecto, no se trata de una simple ideología económica, sino más bien de toda una manera de diferenciarse del poder y de constituirse a la par como público crítico. El neoliberalismo sería el lugar de donde procede gran parte de las actuales críticas contra el Estado; o inversamente, el oscuro fondo desde el cual recibimos y heredamos nuestra actual racionalidad de gobierno. Foucault sostenía que el neoliberalismo alemán elabora otro modo de percibir, de calcular y de resolver problemas: otra racionalidad gubernamental. Si ello fuera cierto, convendría añadir enseguida que el gobierno neoliberal no sólo actúa a través de la represión y la violencia -tal y como muchos críticos señalan con frecuencia-, sino además a través del consenso público; vale decir, a través de nosotros mismos, mediante nuestras propias creencias y deseos. 
Pablo Martín Méndez / "Nosotros: el público ilustrado”. Para una [...] /75

Gobernar según la racionalidad neoliberal implica producir conceso sobre ciertas cuestiones o problemas: sólo en este sentido, la fobia antiestatal juega un papel más que fundamental; y sólo así se entienden además las palabras que Foucault pronunciaba a fines de la década de 1970: "Todos los que participan en la gran fobia al Estado, sepan que están siguiendo la corriente y que por doquier se anuncia desde hace ańos y años una disminución efectiva del Estado, de la estatización y de la gubernamentalidad estatizante y estatizada" (Foucault, 2008a, p. 225). La cuestión no consiste sencillamente en reducir el ámbito de injerencia del gobierno, sino en ejercerlo de una manera diferente, en nuevos espacios y con otras tecnologías. Son las tecnologías de control que hacen al nuevo orden interior, aquellas que favorecen la autorregulación de los conflictos y de los peligros sociales (Foucault, 1991, p. 166). Sin lugar a duda, aquí entran en juego los medios masivos de comunicación -incluyendo la prensa, la radio, el cine y la televisión, como también las más recientes "redes sociales"-. No es que los gobiernos neoliberales intervengan directamente sobre los medios; antes que recurrir a semejante aseveración, y a contramano de lo que habitualmente se piensa, decimos más bien que los medios de comunicación pueden ser en si mismos un elemento gubernamental.

Toda una racionalidad atraviesa las tecnologías neoliberales de gobierno. Se trata de solucionar los conflictos y las diferencias a través de la responsabilidad y la iniciativa individual. Es también la creación de un extenso ambiente de competencia donde los individuos sean continuamente incitados a asumir y sopesar los riesgos y los beneficios de sus respectivas acciones; donde la implementación de planes, proyectos y tácticas aparezca como la única forma valedera de comportamiento. Al abordar las cosas con más detenimiento, vemos que el objetivo consiste en disminuir la necesidad de protecciones y de seguridades estatales. Ello nos indica algo bastante importante sobre nuestra propia actualidad, y es que el neoliberalismo no debe pensarse en absoluto como la mera continuación del liberalismo; por el contrario, el neoliberalismo emerge como la respuesta ante las incongruencias de la racionalidad liberal; en el límite, es un intento diferente de gobernar la libertad.

\section{Breves conclusiones}

Hace casi cuarenta años que Foucault planteaba la necesidad de comprender la singularidad histórica del neoliberalismo. Esta tarea sigue aún vigente -especialmente hoy, cuando las críticas neoliberales se han diseminado y generalizado hasta tal punto que ya ni siquiera las percibimos como aquello que fueron en un comienzo-. Si queremos comprender la novedad y la diferencia de nuestro actual orden interior, si en verdad queremos saber quiénes somos hoy, tenemos que pasar en algún momento por el neoliberalismo. Acaso quedaría por ver que allí no hay únicamente una doctrina económica aplicada por derecho, por ideología o por simple imposición, sino también una nueva manera de articular el gobierno de los otros y el gobierno de sí mismo. Tal vez así, con la problematización del neoliberalismo como relación consigo mismo y como racionalidad de gobierno, llevemos todavía más lejos las apuestas de Foucault. Porque una cosa resulta cierta: si Foucault tiene una apuesta de fondo, consiste sin duda en la posibilidad de ser otro, en trabajarse y transformarse constantemente, hasta devenir en algo diferente de lo que ya se es. Para nosotros, el problema pasará entonces por ser distintos a nosotros mismos, o al menos en no ser lo que ahora estamos siendo: unos sujetos atravesados por el neoliberalismo. 


\section{Bibliografía}

— de la Rivière, M. (1823). El orden natural y esencial de las sociedades politicas. Valencia: Benito Monfort.

— Lazzarato, M. (2006). "Para una redefinición del concepto 'biopolítica”. Brumaria. Arte, Máquinas, trabajo inmaterial (7), pp. 71-81.

- Foucault, M. (2008a). Nacimiento de la biopolítica. Curso en el Collège de France (1978-1979). Buenos Aires: Fondo Cultura Económica.

— Foucault, M. (2008b). "Omnes et singulatim: hacia una crítica de la 'razón política”. En Tecnologias del yo y otros textos afines (pp. 95-140). Paidós: Buenos Aires.

- Foucault, M. (2006). Seguridad, territorio, población. Curso en el Collège de France (1977-1978), Buenos Aires: Fondo de Cultura Económica.

— Foucault, M. (1995). “QQué es la crítica [Crítica y Aufklärung]”. Daimwn. Revista Internacional de Filosofia, (11), pp. 5-25.

— Foucault, M. (1991). "Nuevo orden interior y control social". En Saber y Verdad (pp. 163-166). Madrid: La piqueta.

— Foucault, M. (1980) "El ojo del poder”. En Bentham, J., El Panóptico (pp. 9-26). Madrid: La Piqueta.

— Kant, I. (2005). “¿Qué es la ilustración?”. En Ensayos sobre la paz, el progreso y el ideal cosmopolita (pp. 21-31). Madrid: Cátedra. 